\title{
A cultura popular e a formação profissional em educação física: um estudo no estado de Goiás (Brasil)
}

The popular culture and the colege degree in physical education: a study in the state of Goiás (Brasil)

La cultura popular y la formación profesional en educación física: un estudio en la provincia de Goiás (Brasil)

Katiane dos Santos Costa ${ }^{\mathrm{I}}$, Michelle da Silva Flausino"II, Ana Márcia Silva ${ }^{\mathrm{III}}$

\section{Resumo}

Verificou-se como os conteúdos referentes à cultura popular estão sendo apresentados nos currículos de graduação em Educação Física (modalidade bacharelado, presencial) no estado de Goiás, Brasil. Na primeira análise, foram diagnosticados os projetos político-pedagógicos dos 17 cursos ofertados, no estado, pelas Instituições de Ensino Superior, reduzindo para cinco a amostra final para a pesquisa. Concluiu-se que é possível encontrar a presença da cultura popular nos currículos de formação profissional em Educação Física, contudo, em sua maioria, estes conteúdos são tratados de forma hierarquizada, dissolvida e subjugada aos saberes científicos.

Palavras-chave: Cultura popular; Currículo; Educação Superior

\begin{abstract}
The objective of this study was to analyze how the popular culture contents are being introduced in the curriculum of the course of Physical Education (bachelor's degree) in the Goiás State, Brazil. The political-pedagogical projects of Institutions of Higher Education were analyzed, in relation to the 17 undergraduate courses offered in the State. It was concluded that it is possible to find the presence of popular culture in professional training curricula in Physical Education, however, most contents are treated in a hierarchical way, dissolved, and subjugated by scientific knowledge.
\end{abstract}

Keywords: Popular culture; Curriculum; Higher Education

\footnotetext{
${ }^{\text {I } U n i v e r s i d a d e ~ F e d e r a l ~ d e ~ G o i a ́ s ~-~ U F G ~-~ E n d e r e c ̧ o: ~ A v e n i d a ~ E s p e r a n c ̧ a ~ s / n, ~ C a ̂ m p u s ~ S a m a m b a i a ~-~ P r e ́ d i o ~ d a ~ R e i t o r i a ., ~ C E P ~ 74690-900, ~ G o i a ̂ n i a, ~ G o i a ́ s, ~ B r a s i l ~}$ - e-mail: katianesantosc@gmail.com

II Universidade Federal de Goiás - UFG - e-mail: michelle.flausino@gmail.com

III Universidade Federal de Goiás - UFG - e-mail: anamarcia@pq.cnpq.br
} 


\section{Resumen}

Esta investigación analizó cómo se presentan los contenidos acerca de la cultura popular en currículos de Grado en Educación Física (modalidad bacharelado. presencial) en la provincia de Goiás, Brasil. En el primer análisis se examinaron los proyectos político-pedagógicos de los 17 cursos que imparten las Instituciones de Educación Superior en la provincia, reduciendo a cinco la muestra final para la investigación. Se concluyó que es posible encontrar la presencia de la cultura popular en los planes de estudios de formación profesional en Educación Física, sin embargo, la mayoría de estos contenidos son tratados de manera jerárquica, disueltos y subyugados al conocimiento científico.

Palabras claves: Cultura popular; Plan de estudios; Educación universitaria

\section{Introdução}

A formação profissional em Educação Física passou, desde o início do século XX, no Brasil, por diversas mudanças em suas bases curriculares, até chegar à forma atual, com duas modalidades principais: a licenciatura e o bacharelado (BETTI; BETTI, 1996). Considerando este contexto e as características multiculturais brasileiras, buscamos também contribuir com o processo de adequação dos currículos formativos a um conjunto de dispositivos legais que tratam do tema, tais como a Resolução $n^{\circ} 7$ (2004) que institui Diretrizes Curriculares Nacionais para a Educação das Relações Étnico-Raciais e para o Ensino de História e Cultura Afro-Brasileira e Africana, a Resolução no 1 (2012) que estabelece Diretrizes Nacionais para a Educação em Direitos Humanos, e a Resolução Nº 2 (2012) que estabelece as Diretrizes Curriculares Nacionais para a Educação Ambiental.

Assim, a pesquisa teve como problemática a presença da cultura popular e seus conteúdos nos currículos dos cursos presenciais de bacharelado em Educação Física em Goiás, objetivando identificar se os conteúdos referentes à temática investigada apresentam relevância como disciplinas específicas e exclusivas para a discussão ou se compõem parte das ementas, juntamente com outros conteúdos da cultura popular. Buscou, também, verificar se o perfil do egresso inclui esta preocupação com a cultura popular, além de buscar identificar quais conceitos e práticas corporais ligados à cultura popular foram recorrentes nos currículos estudados.

Consideramos que a cultura popular e seus conteúdos são fundamentais para atuação do bacharel no mundo do trabalho, fora do sistema de educação formal, em diversos espaços, instituições e empresas, em que parece inevitável confrontar-se com as problemáticas e necessidades de uma população multicultural, justificando a importância de tal estudo. 


\section{Metodologia}

A presente pesquisa analisou dados parciais de uma pesquisa maior intitulada: "Análise comparativa do perfil da formação profissional em Educação Física: a América Latina em foco" (SILVA, 2013), sob a coordenação de pesquisadores do Laboratório Physis de Pesquisa em Educação Física, Sociedade e Natureza (Labphysis), vinculado à Universidade Federal de Goiás (UFG), Brasil.

Esta pesquisa utilizou a metodologia descritiva exploratória (GIL, 2008), do tipo qualitativa e, para a análise de dados, a metodologia de análise de conteúdo, proposta por Bardin (2009), enfocando nos conteúdos e modos de comunicar, presentes nos documentos estudados. Utilizou-se de descritores para nomear os signos ou elementos identificadores do conceito mais amplo de cultura popular, também utilizado, e outros complementares como "folclore", "jogos tradicionais", "jogos folclóricos", "danças populares" e "animação sociocultural", buscando delimitar a pesquisa. De acordo com a terminologia de Bardin (2009), os descritores são as unidades de contexto que determinam o que será analisado, dentro das unidades de registro, levantando os elementos textuais presentes no material. Para tal levantamento, utilizou-se o software NVivo10® como ferramenta de apoio.

A fonte primária de dados foi constituída pelos Projetos Político-Pedagógicos (PPPs) - que, em algumas instituições de ensino são denominados Projetos Pedagógicos dos Cursos (PPCs) - e, secundariamente, por informações que constam nos sites das instituições formadoras, analisando-se especialmente o perfil do egresso, as grades curriculares e as ementas das disciplinas.

Utilizou-se, para fonte de dados, a base oficial do Ministério da Educação (MEC), denominada eMEC, onde estão as informações relativas às Instituições de Ensino Superior (IES) e cursos de graduação reconhecidos no sistema oficial de ensino, os atos autorizativos das instituições e cursos de educação superior, editados de acordo com os processos regulatórios competentes (BRASIL, 2017).

Considerando os objetivos desta pesquisa, optou-se por fazer um recorte e analisar somente os currículos das IES que oferecem a modalidade bacharelado presencial no estado de Goiás. Localizaram-se, assim, 17 cursos no total, sendo sete situados na capital- Goiânia, dois em Rio Verde e os demais em Anápolis, Ceres, Itumbiara, Jataí, Luziânia, Mineiros, Piracanjuba e Trindade, um em cada destas cidades.

Ressalta-se que, apesar das diretrizes políticas indicarem a importância da transparência e publicização dos PPPs aos interessados, dentre os 17 cursos analisados, apenas cinco disponibilizavam os documentos curriculares completos online, o que limitou o acesso aos dados e alcance dos objetivos desta pesquisa. 


\section{Formação Profissional}

No que diz respeito à origem e à consolidação da Educação Física, a produção acadêmica tem evidenciado os processos e transformações direcionados para a constituição do campo e sua influência nos processos de formação (LAZZAROTTI FILHO; SILVA; MASCARENHAS, 2014). Dentre esses, deu-se destaque a uma importante mudança que ocorreu em 1987: foi criada, a partir da Resolução ${ }^{\circ}$ 03, a modalidade bacharelado (BRASIL, 1987). Com a resolução, foi preciso fazer uma reformulação curricular, a partir de novas diretrizes que permitiam cursos distintos nos cursos de formação profissional no campo da Educação Física; e toda formação passou a ser realizada em quatro anos para ambas as habilitações.

Essa divisão deu autonomia às instituições formadoras na montagem da estrutura curricular, atendendo à determinação de que cursos de licenciatura tivessem, como principal finalidade, a formação de profissionais para atuar no campo escolar; e de bacharelado para formar profissionais em outros campos singulares não escolares, como unidades de saúde, centros de atenção psicossocial, centros de treinamento esportivo e academias. "Essas mudanças representaram importantes contrastes na formação profissional em Educação Física, como também no desenvolvimento da pós-graduação e de pesquisas científicas." (BENITES; SOUZA NETO; HUNGER, 2008, p. 347).

Com base nesse processo histórico, a Educação Física tem sido alvo de constantes debates sobre os fundamentos do conhecimento, fato que reflete nos modelos curriculares e na formação profissional vigente. Ventura (2010) confirma essa ideia, ao dizer que a divisão na formação em Educação Física, nas modalidades bacharelado e licenciatura, interfere e reflete tanto na prática pedagógica quanto na atuação profissional.

Como consequência destes processos, surge a necessidade de atender ao mercado de trabalho, o que leva a divisão da formação e do trabalho em detrimento da integralidade, da apropriação do campo de conhecimento, do seu objeto de estudo, interferindo diretamente no seu papel social profissional (FELÍCIO, 2007).

Considerando essas mudanças, tanto no que diz respeito à formação quanto à atuação, o currículo é uma importante ferramenta discutida e fundamentada na pesquisa ora apresentada. As discussões que dizem respeito à formação estão eminentemente ligadas às concepções de currículo, pois, nele, estão contidas as propostas de desenvolvimento dos estudantes, os programas de ensino e de pesquisas e o direcionamento da formação dos docentes, tornando-o um norteador das teorias e práticas pedagógicas. É uma ferramenta na qual estão presentes interesses políticos e sociais, sendo, assim, foco de preocupação e discussão das entidades formadoras responsáveis pela sua elaboração, como o MEC e os Conselhos de Educação, que se 
mostram abertas a reflexões e à construção de currículos preocupados com a inserção das práticas educacionais que possuam significados para os sujeitos (BEAUCHAMP; PAGEL; NASCIMENTO, 2008).

Ao se levantar as discussões sobre concepções de currículo, questões teóricas de importante relevância são inevitavelmente postas em evidência, tais como: quais domínios científicos e culturais devem ser estudados? De qual forma? E qual conexão social e política se pretende construir? Como esses conceitos vão influenciar na formação do sujeito? Neste contexto, o currículo deve ser considerado como algo versátil e multicultural, instrumento de lutas por acesso e, como tal, uma mudança no modelo vigente hegemônico deve ser pensada (SILVA, 1996).

O currículo defendido, baseado nas ideias de Morgado (2006) e de Silva (1996), apresenta uma concepção de ensino que busca construir uma sociedade mais solidária, heterogênea e multicultural na espacialidade em que vivem os indivíduos. Porém, compreende-se a existência de um currículo que se opõe a essa visão de ensino defendida. Não obstante, o currículo se consolida como principal meio normativo e de ensino, presente nas IES, como nos cursos de bacharelado em Educação Física.

\section{Cultura popular e a formação do bacharel em educação física}

A abertura da Educação Física às ciências humanas permitiu a realização de estudos e pesquisas referentes aos temas relacionados à cultura, à sociedade e à linguagem; tornando-se participante das ciências da cultura, sem perder a sua interface com as ciências da saúde. Compreendendo que o bacharel em educação física transpõe muito do currículo oculto e oficial ao ambiente de realização profissional, e que, por sua vez, este tem seu próprio currículo, sua práxis social e suas ideologias, percebe-se que o elemento cultural está, de um modo ou de outro, relacionado e integrado à sua prática socioprofissional.

O conhecimento e a prática profissional do bacharel em educação física circulam na esfera da cultura, porém, de uma cultura urbana, que se caracteriza pelas diversas rupturas efêmeras e aceleradas, que são dotadas de elementos cada vez mais padronizados nos corpos e das concepções coletivas que fundamentam a imagem desses, aos grupos e indivíduos sociais dessa espacialidade.

A tentativa de transformar a cultura popular em um espaço temático a ser discutido na produção do conhecimento científico em Educação Física é algo recente na sua história, bem como a sua distinção entre as modalidades bacharelado e licenciatura, além dos cursos tecnológicos, que surgiram nos últimos anos (BAPTISTA et al., 2015). A valorização dos temas referentes às culturas faz parte das mudanças que vêm ocorrendo na ciência contemporânea, iniciado entre os anos de 1950 e 1960, na Europa e nos Estados 
Unidos (ORTIZ, 2002). No Brasil, esse movimento ocorreu mais recentemente: nas últimas três décadas; tornando a cultura popular, na sua multiplicidade semântica, um objeto das ciências humanas relacionado à cultura.

As discussões a respeito da cultura popular, no campo do conhecimento científico, são do interesse da Educação Física, assim como a valorização de saberes secundarizados pela ciência moderna - como crendices, folclore e artes circenses, entre tantas outras expressões culturais que se relacionam com os saberes populares ligados às práticas corporais (GRANDO, 2003).

As práticas corporais ligadas à cultura popular representam experiências no processo de formação humana, uma vez que possuem caráter coletivo, de identidade e ritualístico, expressos em várias práticas ligadas à Educação Física - como os jogos e as danças, que contribuem com o processo de inserção social. A cultura popular é um fenômeno vivo e mutável, não admitindo o status estagnado de "folclore'. Ela faz parte dos saberes silenciados pela hierarquização do conhecimento e é em suas diferenças e contradições que está sua ressignificação, as quais se podem visualizar em várias manifestações populares (GRANDO, 2003).

Dentre as diversas formas de expressão corporal de interesse da Educação Física, e ligadas à cultura popular, a capoeira figura como um importante elemento de exemplificação da transcendência e mobilidade da cultura. Ela tanto se configura como parte de uma constituição histórica antropológica da cultura brasileira, quanto também como um objeto de apropriação do mercado, levada para academias de ginástica, para atender a uma demanda que se apropria e ressignifica às práticas populares em espaços diferentes daqueles em que foram originadas (SILVA; FALCÃO; DIAS, 2012). Essa prática não é proibida, pois a cultura é modificada constantemente. Contudo, é necessário que os profissionais que se propõem a trabalhar com essas temáticas tenham domínio dos elementos culturais constituintes dessas práticas e conhecimento da importância e do significado das mesmas, pois se tratam de elementos da realidade de diversos grupos sociais, reconhecendo esses grupos enquanto sujeitos protagonistas (SBORQUIA; NEIRA, 2008).

Dentre os debates ligados às concepções de currículo estão incluídas as correlações de conhecimento científico e cultura popular, como reconhecimento da multiculturalidade e da diversidade dos componentes do processo de aprendizagem em consonância com a produção humana. Sob esse viés, o currículo é uma peça fundamental para a educação, perpassando o direito social e dos sujeitos, levando em consideração os saberes, símbolos, memórias, identidade e valores culturais como parte do desenvolvimento humano (MOREIRA; CANDAU, 2008).

Desse modo, os conteúdos inseridos na formação dos bacharelandos em Educação Física, no espaço formal e científico, são elementos utilizados para atender às demandas que surgem a partir da 
mercantilização do corpo (SILVA, 2001). Esse fato leva a observar que os conteúdos da cultura popular são colocados em segundo plano nos currículos da Educação Física, por serem considerados elementos vindos do povo, o oposto da cultura erudita e não pertencente às elites; consequentemente, não podem figurar no currículo das instituições formadoras (SANTOMÉ, 1998 apud SBORQUIA; NEIRA 2008).

\section{Os currículos e a cultura popular: análise dos dados}

Os dados indicam que, destes 17 cursos estudados, dois são vinculados a instituições públicas e 15 a instituições privadas, predominando a carga horária de $3.200 \mathrm{~h}$, com algumas dissonâncias, como é o caso do curso do Centro Universitário de Mineiros (UNIFIMES), com 7.704h, e o da Universidade Federal de Goiás (UFG), Regional Jataí, com 2.400h. A maior parte dos cursos foi criada nas últimas décadas do século XX, sendo que o curso da Universidade de Rio Verde (UniRV) é o mais antigo, criado em 1998, e o da Faculdade de Piracanjuba (FAP), o mais recente, com o início do curso em março de 2016.

Em termos de área de concentração ou enfoque, os temas mais frequentes entre as instituições analisadas foram o esporte e o lazer, como é o caso da Associação Salgado de Educação e Cultura (UNIVERSO), e o enfoque no campo da saúde pública, como é o caso de ambos os cursos da Universidade Federal de Goiás (UFG), Campus Goiânia e Campus Jataí.

Nas instituições acima mencionadas, a diferença desdobra-se na quantidade de disciplinas e créditos voltados para consolidar o enfoque previsto no PPP, reforçando os diferentes perfis de egresso e a capacitação para diferentes espaços e atuações no mundo do trabalho. Chama a atenção a distinção polarizada entre a instituição pública e seus dois campi e a instituição privada: a primeira, voltada para o que denomina de "Educação Física, Saúde e Sociedade" e um conjunto amplo e significativo de disciplinas para sustentar esta atuação, tais como "Práticas Corporais e Promoção da Saúde" e "Gestão e Políticas de Educação Física e Saúde", sobretudo considerando a possibilidade concreta de participação dos profissionais de Educação Física nas equipes multidisciplinares que compõem o Sistema Único de Saúde (SUS). E a segunda, com enfoque no treinamento esportivo, demonstrado no número de disciplinas voltado para esse tipo de conteúdo, tais como "Organização e Administração Esportiva", "Treinamento Desportivo I", além dos diferentes esportes individuais e coletivos.

Apesar destas diferenças, a presença da cultura popular e suas temáticas é pontual e secundária em ambas as instituições e nos três cursos. Essa condição se repete em praticamente todos os cursos analisados. Ressalta-se que, de acordo com os documentos analisados, todos os cursos apresentam a informação de que se pretende desenvolver um processo de formação ampliada, porém, observou-se que não parece haver uma 
consideração adequada à diversidade cultural e das manifestações da cultura corporal em suas contribuições para a formação humana, saúde e lazer.

As diferenças de enfoque e direcionamento entre os cursos pode ser um reflexo das preocupações e prioridades das instituições. Uma hipótese que poderia ser levantada é que as instituições privadas intencionam atender a demandas de mercado, como é o caso das academias e escolas de esporte que possuem mais aceitação e demanda e, consequentemente, de maior busca pelo curso por conta do potencial de empregabilidade. Em contrapartida, as públicas visam, em princípio, não somente uma formação para atender ao mundo do trabalho, mas também uma devolutiva às demandas de políticas públicas e sociais, como as práticas comunitárias e disciplinas voltadas para a saúde coletiva nos estágios que acontecem em espaços e equipamentos públicos, valorizando os vínculos com a comunidade local.

Dentre as instituições analisadas, observou-se que o principal enfoque, em termos de perfil desejado do egresso, predomina um direcionamento para uma futura atuação em múltiplas áreas, como lazer, recreação, saúde, treinamento esportivo, condicionamento cardiorrespiratório por meio de exercícios físicos e, também, reabilitação. O intuito central da formação parece ser o de qualificar profissionais nos mais variados campos informal e formal para atender a crescente e diversificada demanda do mercado consumidor de bens relacionados a um corpo saudável

Nos cursos analisados, parece predominar uma concepção teórico-prática voltada a uma lógica urbana e padronizada, com ênfase nos esportes convencionais, além de promover certa invisibilidade de corpos diferentes, como a literatura acadêmica têm discutido. Isso porque nem todos querem ou têm acesso e condições para fazer parte deste mercado criado apologeticamente como o ideal à saúde dos corpos para atender as exigências da sociedade no sistema capitalista (BAPTISTA, 2007).

Ao analisar os dados disponíveis, verificou-se a presença da cultura popular principalmente apenas na forma de disciplinas optativas e em poucas das instituições analisadas. Este dado leva a crer que há uma não priorização de tais temáticas no currículo, o que pode indicar certo privilégio de elementos advindos de uma cultura tradicional, em geral de matriz europeia e ou norte-americana, como é o caso dos modelos de esporte convencional e dos conteúdos biomédicos no trato com o corpo humano.

Parece ser relevante frisar a ausência do termo "cultura popular" no título de todas as disciplinas de todos os PPPs, inclusive nos das que não tinham documentação completa. Cabe, então, questionar: por que cultura popular não aparece nos títulos das disciplinas, mas é mencionada na apresentação dos PPPs e em outros elementos? E ainda: por que aparece em maior quantidade nas instituições públicas do que nas privadas? A partir dos dados da pesquisa, é possível inferir que parece não existir uma real apropriação dos espaços acadêmicos que intercale o saber científico e o saber popular; e que este, por sua vez, é 
secundarizado diante da hierarquia dos saberes (GRANDO, 2003). Ainda que não seja com grande expressão, as instituições públicas, ao trazerem, para sua apresentação de programa, as bibliografias e o perfil do egresso, o termo cultura popular, parecem indicar uma intencionalidade em construir um discurso que acolha as diferenças e prepare seus profissionais para minimamente conhecer e trabalhar com essa abordagem. Em contrapartida, não está claro o interesse das instituições privadas no trato com a cultura popular por se tratar de um campo de conhecimento não vinculado diretamente à lógica de mercado (BETTI; BETTI, 1996).

Seguindo os passos metodológicos previstos, o refinamento da análise passou a identificar os descritores, as práticas e os conceitos relativos que a literatura correlaciona com a cultura popular (GREGÓRIO; WIGGERS; ALMEIDA, 2014; ALMEIDA, 2012). Além do descritor principal - “cultura popular", outros descritores complementares foram utilizados, como "folclore", "jogos tradicionais", “jogos folclóricos”, “danças populares” e “animação sociocultural”, como já mencionado.

Com apoio de ferramenta tecnológica NVivo10®, foi possível visualizar quais termos têm maior frequência de uso nos documentos analisados. Observou-se que o descritor "cultura popular", aparece apenas em $109^{\circ}$ lugar do total dos termos mais frequentes, atrás de termos como "lazer", "ginástica" e "esporte", sendo que este último perde apenas para os termos "educação" e "física" neste levantamento. Os demais descritores secundários utilizados nesta pesquisa estão ainda mais distantes e menos frequentes do que cultura popular. Tais indicadores evidenciam a cultura popular apresentada e relacionada com outros termos de forma indireta, não estão ligados à perspectiva formativa diretamente associada à cultura popular. O resultado reforça a ideia de Neira e Nunes (2011) de que o bacharelado segue o paradigma da padronização dos corpos, produzindo uma cultura única, na qual a diversidade contida na cultura popular é secundarizada. Os mesmos autores informam que, neste jogo, os grupos que detêm o poder simbólico definem o válido, afirmam para si a condição de identidade e o padrão a ser seguido, bem como representam o outro como diferente, alguém a ser corrigido ou deixado às margens das condições sociais (NEIRA; NUNES, 2011).

Assim, infere-se que, por mais que haja diferenças entre as instituições e entre os cursos de bacharelado em Educação Física no Estado de Goiás, os resultados desse levantamento indicam muito mais similaridades do que divergências, ao menos no que diz respeito ao trato com a cultura popular.

O descritor "cultura popular" foi encontrado apenas nas bibliografias básicas e complementares dos cursos da instituição pública e em apenas uma das instituições privadas, a Associação Salgado de Educação e Cultura (UNIVERSO), sendo que nesta foi possível identificar também no conteúdo programático e na ementa várias disciplinas. 
Os dados obtidos a partir do termo "cultura popular" aparecem na bibliografia básica da UFG Regional Goiânia, nas disciplinas "Introdução aos Estudos do Lazer", com o livro "Lazer e cultura Popular", de Joffre Dumazedier, e em "Pesquisa e Ensino em Dança”, com o livro "O que é cultura popular", de Mario de Andrade. Também, na bibliografia complementar, em "Fundamentos SócioPedagógicos das Lutas", no livro "O jogo da capoeira”, de Luiz Carlos Vieira Tavares. O curso na UFG Regional Jataí segue a mesma linha e também tem como referência do componente curricular "Introdução ao Estudo do Lazer", o livro de Dumazedier citado acima. Entende-se que as bibliografias constituem parte importante dos programas, pois nelas estão contidos os referencias teóricos que fundamentam a formação e a intervenção do futuro profissional.

Com referência ao estudo desenvolvido nas ementas das disciplinas, o descritor "cultura popular" foi encontrado nas disciplinas de Handebol e Basquetebol da UNIVERSO, em que, segundo as ementas das referidas disciplinas, objetiva-se desenvolver habilidades de seleção e sistematização de diferentes jogos da cultura popular para desenvolver o trabalho tático; portanto, instrumentalizando conteúdos da cultura popular para o treinamento esportivo. O descritor também foi identificado no conteúdo programático da disciplina "Sociologia Aplicada", na qual se explicita trabalhar a essência dos diferentes tipos de cultura, dentre elas a cultura popular. Na disciplina "Atletismo", deste mesmo curso, identifica-se a intenção de trabalhar com elementos e com a sistematização de diferentes movimentos da cultura popular.

Considerando que o conceito de cultura popular é de difícil definição e polissêmico (NEIRA; NUNES, 2011), os outros descritores utilizados como "folclore", "jogos tradicionais", "jogos folclóricos", “danças populares" e "animação sociocultural”, permitiram ampliar o leque de análise e o resultado foi consideravelmente alterado.

A alteração materializou-se na maior quantidade de elementos vinculados à cultura popular, seja nas apresentações, ementas, bibliografias básicas e complementares, perfil do egresso, conteúdo programático e em matriz curricular. O resultado tornou possível identificar uma maior presença da cultura popular, por meio destes descritores secundários, mesmo que de forma difusa e de modo até mais expressivo, nas instituições privadas do que nas públicas.

Ao buscar-se apenas o descritor "cultura popular", foi observado relevância pouco significativa à temática, o que evidencia uma fragmentação do conceito, em uma tentativa de coexistir em meio ao sistema educacional vigente. Como já dito, trata-se de um termo que agrega várias manifestações e é mutável; porém, há características que delimitam esse conceito, como a forma de transmissão de saberes, e, como tal, não devem ser desconsideradas. Assim, em seguida foram relacionados alguns dos termos encontrados 
com o termo "cultura popular", mas não se deixou de ressaltar que a cultura popular segue uma lógica própria.

O termo "jogo", por exemplo, é referenciado de várias maneiras nos documentos analisados: "jogos tradicionais", “jogos folclóricos”, “jogos coletivos” e pode ser sim considerado popular, uma vez que é comum em várias regiões do Brasil. Carrega consigo elementos próprios da cultura popular, como oralidade e memória, assim como a capoeira, que foi encontrada como conteúdo de disciplinas e bibliografias básicas e complementares de quatro dos cinco documentos analisados. A capoeira também traz consigo a ancestralidade e a ritualidade, constituintes de sua matéria e integrantes de outras manifestações, como samba, violeiros e artesãos (ABIB, 2004). Atende às duas vertentes, a mercadológica e a social; em seu caráter popular tem uma direção com finalidades distintas da lógica de mercado, com intuito da socialização e das trocas de experiências sem precisar de meios midiáticos para se difundir. Porém, como é o caso dos já citados jogos e da capoeira, estes também podem ser usados como bens de consumo; é o caso dos jogos esportivos institucionalizados e da capoeira que vai para as academias e é exportada para outros países.

A configuração mais comum com que a cultura popular adentra nos currículos é por vias fragmentadas e invisibilizadas, em uma comum associação da mesma com o termo "folclore". Consequentemente, associada com as festas e datas comemorativas as quais o termo remete, resultando em uma degeneração e uma visão deturpada, em que tudo é cultura, terminando por desconsiderar os valores identitários desta temática. Ao encontrar os conteúdos da cultura popular dissolvidos, é possível afirmar que as práticas de determinados grupos também são diluídas e, com tal movimento, homogeneizadas, desconsiderando a multiculturalidade parte do sujeito, característica essa que deveria fazer parte do seu processo de formação profissional.

Sendo assim, analisar esse contexto se torna relevante, considerando a formação pretendida pelas instituições, de modo a diminuir as discrepâncias na ordenação dos saberes e promovendo a interlocução dos mesmos nos processos educativos do sujeito.

\section{Considerações finais}

O conceito de cultura popular é complexo e abrangente, considerado polissêmico pela literatura científica (DOMINGUES, 2011), e com potencial emancipatório. Pode não ser de fácil conceituação, porém, faz parte dos processos identitários de maneira direta e indireta. Apesar disso, não é considerado com a devida dimensão nos espaços formadores, sendo secundarizado e diluído em meio aos esforços de 
uma padronização dos corpos, hábitos e costumes, como indica a análise dos documentos das instituições realizada nesta pesquisa.

Conclui-se, então, a partir dos documentos analisados nos cursos de bacharelado em Goiás, modalidade presencial, por meio dos dados, que é possível encontrar conteúdos vinculados à cultura popular nos processos de formação profissional. A temática investigada, contudo, não está evidenciada em nenhum título das disciplinas e aparece, eventualmente, em algumas ementas ou no perfil do egresso, conforme alguns documentos institucionais. Aparece, também, nas referências bibliográficas como um elemento importante na formação, considerando a abrangência e diversificação de atuação profissional do bacharel. No entanto, o grande predomínio dos conhecimentos e referencias ligados aos esportes convencionais e ao campo biomédico, sugere que os conteúdos da cultura popular são tratados de forma hierarquizada, dissolvida e subjugada pelos saberes científicos (GRANDO, 2003), talvez, porque estes conteúdos não se enquadrem tão facilmente na lógica do mercado que visa lucro e resultados.

Ressalta-se o fato de não ter sido desenvolvida a análise dos livros e dos autores que fundamentam os currículos das instituições estudadas e, desta forma, as análises dos conceitos e indicações de práticas corporais ligados à cultura popular não foram possíveis de serem aprofundadas. Outro limite desta pesquisa é o fato de não se ter tido acesso a todos os documentos das 17 instituições formadoras, o que possibilitaria um mapeamento mais completo relativo ao Estado de Goiás.

Por fim, ressalta-se que os resultados deste estudo suscitam novas reflexões e a percepção de que as diferenças e os saberes populares não estão sendo abordados adequadamente. Parece que as instituições não consideram a ampla gama de manifestações culturais que podem constituir as intervenções em Educação Física e todo o potencial existente em suas mais variadas manifestações e em todos os sentidos e significados humanos que representam (KUNZ, 1991).

\section{Referências}

ABIB, Pedro Rodolpho Jungers. Capoeira angola: cultura popular e o jogo dos saberes na roda. Resgate: Revista Interdisciplinar de Cultura, Campinas, v. 12, n. 1, p. 171-176, 2004.

ALMEIDA, Dulce Filgueira de. Corpo, cultura e sincretismo: o ritual da congada. Pensar a Prática, Goiânia, v. 15, n. 1, p. 1ᄀ271, jan./mar. 2012. Disponível em revistas.ufg.br/fef/article/view/18012/10740. Acesso em: 29 jun. 2021.

BAPTISTA, T. J. R. Educação do corpo: produção e reprodução. 2007. Tese (Doutorado em Educação) Faculdade de Educação, Universidade Federal de Goiás, Goiânia, 2007. 
BAPTISTA, T. J. R.; LEITE, J. O.; FALCÃO, J. L. C; FLAUSINO, M. S. Perfil atual da formação profissional da educação física no Brasil. In: SILVA, A. M.; BEDOYA, V. M. (org.). Formação profissional em educação física na América Latina: encontros, diversidades e desafios. Jundiaí: Paco Editorial, 2015. cap. 3. p. 55-75.

BARDIN, L. Análise de conteúdo. Lisboa, Portugal: Edições 70, 2009.

BEAUCHAMP, J.; PAGEL, S. D.; NASCIMENTO, A. R. (org.). Indagações sobre currículo: currículo, conhecimento e cultura. Ministério da Educação, Secretaria de Educação Básica: Brasília, 2008. Disponível em: http://portal.mec.gov.br/seb/arquivos/pdf/Ensfund/indag3.pdf. Acesso em: 20 jul. 2016.

BENITES, L. C.; SOUZA NETO, S.; HUNGER, D. O processo de constituição histórica das diretrizes curriculares na formação de professores de Educação Física. Educação e Pesquisa, São Paulo, v. 34, n. 2, p. 343-360, maio/ago. 2008. Disponível em: http://www.scielo.br/pdf/ep/v34n2/09.pdf. Acesso em: 20 jul. 2016.

BETTI, M.; BETTI, I. C. R. Novas perspectivas na formação profissional em Educação Física. Revista Motriz, Rio Claro, v. 2, n. 1, p.10-15, jun. 1996. Disponível em: http://www.rc.unesp.br/ib/efisica/motriz/2n1.htm. Acesso em: 28 jun. 2016.

BRASIL. Ministério da Educação. Conselho Nacional de Educação. Resolução nº 03/1987, de 16 de jun. de 1987. Fixa os mínimos de conteúdo e duração a serem observados nos cursos de graduação em Educação Física (Bacharelado e/ou Licenciatura Plena). Brasília: CNE, 1987.

BRASIL. Ministério da Educação. Conselho Nacional de Educação. Resolução nº 07/2004, 31 mar. 2004. Institui as Diretrizes Curriculares Nacionais para os cursos de graduação em Educação Física, em nível superior de graduação plena. Diário Oficial da União, Brasília, 5 de abril de 2004, Seção 1, p. 18. Disponível em: http://portal.mec.gov.br/cne/arquivos/pdf/ces0704edfisica.pdf. Acesso em: 9 jan. 2017.

BRASIL. Ministério da Educação. Conselho Nacional de Educação. Resolução no 1, de 30 de mai. de 2012. Estabelece Diretrizes Nacionais para a Educação em Direitos Humanos. Brasília: MEC, 2012 a. Disponível em: http://portal.mec.gov.br/dmdocuments/rcp001_12.pdff. Acesso em: 9 jan. 2017.

BRASIL. Ministério da Educação. Conselho Nacional de Educação. Resolução no 2, de 15 de jun. de 2012. Estabelece Diretrizes Curriculares Nacionais para a Educação Ambiental. Brasília: MEC, 2012 b. Disponível em: http://portal.mec.gov.br/dmdocuments/rcp002_12.pdf. Acesso em: 9 jan. 2017.

BRASIL. Ministério da Educação. Instituições de educação superior e cursos cadastrados. Brasília: MEC, 2017. Disponível em: http://emec.mec.gov.br/. Acesso em: 12 jan. 2017.

DOMINGUES, P. Cultura popular: a construção de um conceito na produção historiográfica. História, São Paulo, v.30, n.2, p. 401-419, ago./dez. 2011. Disponível em: https://www.scielo.br/j/his/a/TX6Cn5qhr85zFwnKbkpBZtK/?format=pdf\&lang=pt. Acesso em: 22 set. 2021.

FELÍCIO, B. F. Em busca dos fundamentos da proposta de bacharelado em educação física: das justificativas teóricas do curso à atividade profissional na área. In: CONGRESSO BRASILEIRO DE CIÊNCIAS DO ESPORTE, 15., Recife. Anais eletrônicos [...]. Recife: CBCE, 2007. p. 1-10. Disponível em: http://www.cbce.org.br/docs/cd/resumos/184.pdf. Acesso em: 20 jul. 2016. 
GIL, A. C. Métodos e técnicas de pesquisa social. São Paulo: Atlas, 2008.

GRANDO, B. S. Corpo educação: relações interculturais nas práticas corporais Bororo em Meruri-MT. Motrivivência, Florianópolis, v. 15, n. 20-21, p. 201-209, mar./dez. 2003. Disponível em: https://periodicos.ufsc.br/index.php/motrivivencia/article/view/918/4150. Acesso em: 21 jun. 2016.

GREGORIO, L. V.; WIGGERS, I. D. W.; ALMEIDA, D. F. “Isso é aula de Educação Física?” Práticas Corporais na Escola. Pensar a Prática, Goiânia, v. 17, n. 4, out./dez. 2014. Disponível em: https://www.revistas.ufg.br/fef/article/view/30234. Acesso em: 23 mar. 2016.

KUNZ, E. Educação Física: ensino \& mudanças. Ijuí, UNIJUI Editora, 1991.

LAZZAROTTI FILHO, A.; SILVA, A. M.; MASCARENHAS, F. transformações contemporâneas do campo acadêmico-científico da educação física no Brasil: novos habitus, modus operandi e objetos em disputa. Movimento: Porto Alegre, v. 20, n. esp., 2014. p 67-80. Disponível em: https://seer.ufrgs.br/Movimento/article/download/48280/32814. Acesso em: 20 set. 2021.

MOREIRA, A. F. B.; CANDAU, Vera Maria. Currículo, conhecimento e cultura. In: BEAUCHAMP, J.; PAGEL, S. D.; NASCIMENTO, A. R. (org.). Indagações sobre currículo: currículo, conhecimento e cultura. Ministério da Educação, Secretaria de Educação Básica: Brasília, 2008. p. 17-43 Disponível em: http://portal.mec.gov.br/seb/arquivos/pdf/Ensfund/indag3.pdf. Acesso em: 20 jul. 2016.

MORGADO, J. C. Globalização e (re) organização do ensino superior: perplexidades e desafios. Perspectiva, Florianópolis, v. 24, n. 1, p. 205-228, 2006.

NEIRA, M. G.; NUNES, M. L. F. Contribuições dos estudos culturais para o currículo da educação física. Revista Brasileira de Ciências do Esporte, Porto Alegre, v. 33, n. 3, p. 671-685, jul./set. 2011. Disponível em: http://www.scielo.br/scielo.php?script=sci_arttext\&pid=S010132892011000300010. Acesso em: 21 jul. 2016.

ORTIZ, R. As ciências sociais e a cultura. Tempo social, São Paulo, v. 14, n. 1, p. 19-32, 2002.

SBORQUIA, S. P.; NEIRA, M. G. As danças folclóricas e populares no currículo da Educação Física: possibilidades e desafios. Revista Motrivivência, Florianópolis, v. 20, n. 31, p. 79-98, dez. 2008. Disponível em: https://periodicos.ufsc.br/index.php/motrivivencia/article/viewFile/21758042.2008n31p79/12957. Acesso em: 23 jun. 2016.

SILVA, A. M. Corpo, ciência e mercado: reflexões acerca da gestação de um novo arquétipo da felicidade. Campinas/Florianópolis: Autores Associados/EDUFSC, 2001.

SILVA, A. M. et al. Análise comparativa do perfil da formação professional em educação física: a América Latina em foco. Projeto de Pesquisa da Universidade Federal de Goiás. Goiânia: FEFD/UFG, 2013.

SILVA, R. de L.; FALCÃO, J. L. C.; DIAS, C. G. Discursos sobre a tradicionalidade da capoeira angola: a influência e o papel dos capoeiristas. Cultures- Káiros, França, v.1 n.1, dez.2012. Disponível em: https://revues.mshparisnord.fr/cultureskairos/index.php?id=489. Acesso em 23 jun.2016. 
SILVA, T. T. da. Identidades terminais: as transformações na política da pedagogia e na pedagogia da política. Petrópolis: Vozes, 1996.

VENTURA, P. R. V. A Educação Física e sua constituição histórica: desvelando ocultamentos. 2010. Tese (Doutorado em Ciências Humanas) - Pontifícia Universidade Católica de Goiás, Goiânia, 2010.

\section{Como citar este artigo}

COSTA, K. S.; FLAUSINO, M. S. SILVA, A. M. A cultura popular e a formação profissional em educação física: um estudo no estado de goiás (Brasil). Revista Kinesis, Santa Maria, v. 39, p.01$15,2021$.

* Este estudo não contou com apoio financeiro de nenhuma natureza para sua realização. 